\title{
Performance characteristics of a small water-hammer head pump
}

\author{
Krishpersad Manohar, Anthony Ademola Adeyanju, and Kureem Vialva \\ Mechanical and Manufacturing Engineering Department, The University of the West Indies, St. Augustine, \\ Trinidad, West Indies \\ Correspondence: Krishpersad Manohar (krishpersad.manohar@sta.uwi.edu)
}

Received: 8 April 2019 - Discussion started: 23 April 2019

Revised: 16 September 2019 - Accepted: 1 October 2019 - Published: 5 November 2019

\begin{abstract}
Many rural farming areas are located far from a reliable electricity supply; hence, obtaining a reliable source of water for crops and livestock can prove to be an expensive venture. A water pump operating on the water-hammer effect requires no external power source and can serve as an effective means of pumping water to a higher altitude once a reliable supply is available. A low-cost small water-hammer head pump was designed to operate on the water-hammer head effect created by the sudden stoppage of a flowing fluid. This design consisted of an inlet section followed by the pump body, a pressure section and an outlet. The experimental set-up for testing the water-hammer head pump was designed with a variable head input and an adjustable head output. For each test configuration, a total of 10 samples of pump supply water and pump exhausted water were collected. The water samples were collected for $30 \mathrm{~s}$ in each case. The results showed a non-linear variation of water flow with respect to pump outlet height. The pump was capable of delivering water to a maximum height of 8 to 10 times the height of the input head. The pump operated at average efficiencies of $26 \%, 16 \%$ and $6 \%$ when the delivery height was 2, 4 and 6 times the input head height, respectively. There was a $5 \%$ incremental decrease in pump efficiency as the delivery height increased in increments of the corresponding input head height.
\end{abstract}

\section{Introduction}

The first type of pump to use the water-hammer effect was the hydraulic ram pump which was reported in 1775 and built by Whitehurst (1775). His design was not automatic and was controlled by manually opening and closing a stopcock which resulted in the device only being able to raise water to a height of $4.9 \mathrm{~m}$. This involved a significant amount of work and was very time-consuming to operate. However, in 1797 the design was improved and the first reported automatic hydraulic ram was developed by Joseph and Etienne Montgolfier to raise water to a paper mill (De Montgolfier, 1803). Although this was an improved design, it still contained design flaws that caused the air in the pressure chamber to dissolve or drop. In 1816 this problem was eliminated when Pierre Montgolfier designed the sniffer valve that reintroduced the introduction of air into the chamber. This valve was $15 \mathrm{~cm}$ in radius, and it was reported that the pump was then able to raise water to a height of $48 \mathrm{~m}$ (Mohammed,
2007). The automatic hydraulic ram has been used for centuries to lift water to heights of over $100 \mathrm{~m}$ and is considered to be an effective and highly reliable machine for pumping water once certain conditions are satisfied. The pump construction is simple and consists of a pump chamber fitted with two moving parts: an impulse valve through which the driving water is wasted and a delivery valve through which the water is delivered (Berganta et al., 2006). The pump operates solely on the power supplied from the water head in the source. This source could be a spring, stream, river, pond, dam, lake or even some wells, as long as the conditions exist for these water sources to create a hydraulic flow head, either by forming a dam or a naturally existing head. Basically, once a hydraulic head can be created, the pump can operate; however, the source must provide a steady and reliable supply of water (Yao et al., 2015). The ram pump must also be installed at a location lower than that of the water source that 
was used to create the flow, thereby giving the fluid (water) some velocity.

In many rural farming areas, having a reliable source of water for crops and livestock can prove to be an expensive venture. In developing and underdeveloped countries, farmlands are ideally located close to a reliable water source to ensure viability (Water Service, 2004; Dzvurumi, 2006) However, in many instances these locations are far from any reliable source of electricity; hence, the cost of obtaining water can be prohibitive (Water Service, 2004; Food Security Support Programme, 2011). The alternative diesel-driven pumps are associated with high operational costs and are prone to service gaps due to insufficient fuel supply and technical defects. Therefore, a reliable and cost-effective supply of irrigation water is a core problem in many rural areas in developing and emerging countries (Garg, 1987). In cases where the water source is situated below the level of the farmlands, getting the water to where it is needed can be challenging (Dzvurumi, 2006). Under these circumstances, a water pump operating on the water-hammer effect that requires no external power source can serve as an effective means of pumping water to a higher altitude once a reliable source is available. In underdeveloped countries, such as Haiti, the feasibility of using small water-hammer head pumps to provide clean water for citizens has already been explored by Prude University (Engel and Ahiablame, 2012). A ram pump can operate 24/7; hence, a water storage facility, such as storage tanks, at the water delivery end is needed. This serves as the reservoir to supply water as required. The major hindrance to using this established technology in third world countries is the exorbitant cost of the commercially available units: for a pump built in the UK the cost is USD 1800 (Papa Hydraulic Ram Pump, 2019), whereas cheaper pumps made in China range between USD 500 and USD 1300 (Water Powered Technologies, 2019). One of the objectives of the Prude University project in Haiti was to develop a cheaper alternative; however, the cost of the unit developed was still USD 100 (Engel and Ahiablame, 2012). Therefore, the need to develop a lowcost alternative that can be easily built from readily available construction materials and requires minimal technical skills still exists.

Given the long history of the hydraulic ram pump, the design and manufacture has improved considerably over time, and the efficiency of operation has increased. For commercial ram pumps the typical energy efficiency is about $60 \%$, but can reach up to $80 \%$ (Asvapoositkul et al., 2019). This is different from the volumetric efficiency, which relates the volume of water delivered to the total water taken from the source. The amount of water delivered will be reduced by the ratio of the output head to the supply head. For example, if the source is $2 \mathrm{~m}$ above the ram pump and the water is lifted to $10 \mathrm{~m}$ above the pump, only $20 \%$ of the supplied water will be available and the other $80 \%$ will be spilled via the exhaust valve (Young, 2016). These ratios assume $100 \%$ energy efficiency. The actual water delivered is reduced further by the energy efficiency. Hence, for an energy efficiency of $70 \%$, the water delivered will be $70 \%$ of $20 \%$, which yields $14 \%$ (Young, 2016; Lansford and Dugan, 1941). Suppliers of ram pumps often provide tables giving expected volume ratios based on actual tests. The amount of water delivered to the end for use will depend on the source flow, the height of supply reservoir above the pump, the height of delivery site above the pump, the length and size of the delivery pipe and the drive line, the pump efficiency, and the size of the pump (Lansford and Dugan, 1941; Taye, 1998; U.S. Department of Agriculture Natural Resources Conservation Service, 2007). Considering the many combinations of these variables, the amount of water that can be delivered varies significantly. For example, the delivery output from a single $2^{\prime \prime}$ ram pump system can range from a low of $64 \mathrm{Ld}^{-1}$ to $15000 \mathrm{Ld}^{-1}$ or more (U.S. Department of Agriculture Natural Resources Conservation Service, 2007).

Apart from the fact that the delivery output of the hydraulic ram pump depends on many variables, the design itself is complicated by the three-pipe flow system and the hydraulic ram effect (Tijsselingc and Berganta, 2012). The delivery output is a non-linear relationship with input head and output head variables. Therefore, for a specific hydraulic ram pump, determining the delivery output at variable input and output head heights is a critical factor in determining the applicability, suitability and effectiveness for use. This study investigates the performance characteristics of a low-cost hydraulic ram pump with input and delivery head height variation and quantifies the change in efficiency with respect to the water delivered.

\section{Materials and methods}

The small water-hammer head pump was designed to operate on the water-hammer head effect created by the sudden stoppage of a flowing fluid. The main components of the pump operation involved two one-way valves and a pressure tank. The one-way valves were arranged such that when one closed the other opened and vice-versa. This design consists of an inlet section followed by the pump body, a pressure section and finally an outlet. A $24.5 \mathrm{~mm}$ PVC ball valve was installed at the inlet section that allowed for control of the water entering the body of the pump and facilitated priming of the pump. The pump was constructed using $32 \mathrm{~mm}$ diameter PVC pipe and valves. The advantages of this material were the low cost, the low coefficient of friction and the resistance to corrosion. Brass one-way swing valves were also used in the design. Another $13 \mathrm{~mm}$ PVC ball valve was placed on the outlet pipe of the pump to prevent back-flow and drainage of the supplied water when the pump was not operating. Figure 1 is a schematic showing the main components of the pump design.

The pressure tank was constructed using a $127 \mathrm{~mm}$ long $75 \mathrm{~mm}$ diameter PVC pipe. A PVC end caps was used on one end of the pipe and reduction PVC fittings on the other 


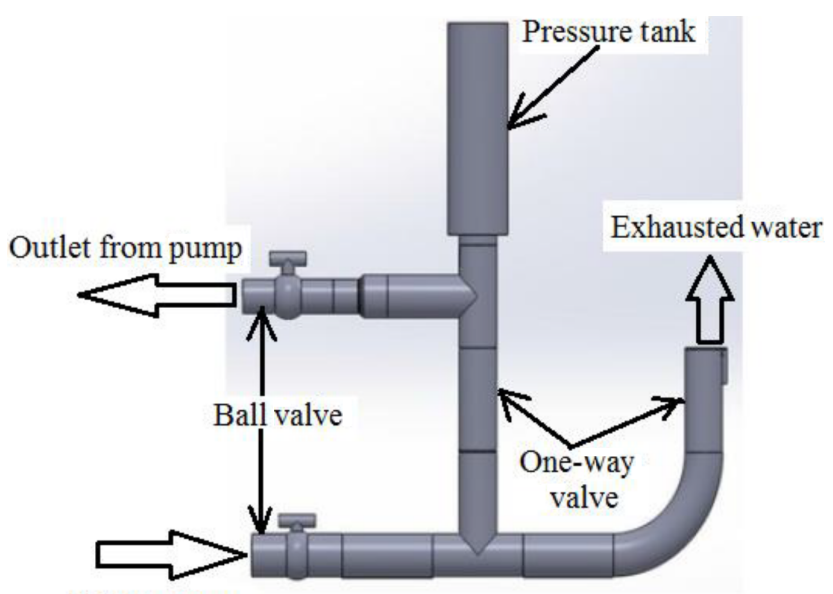

Inlet to pump

Figure 1. Schematic of the water-hammer head pump.

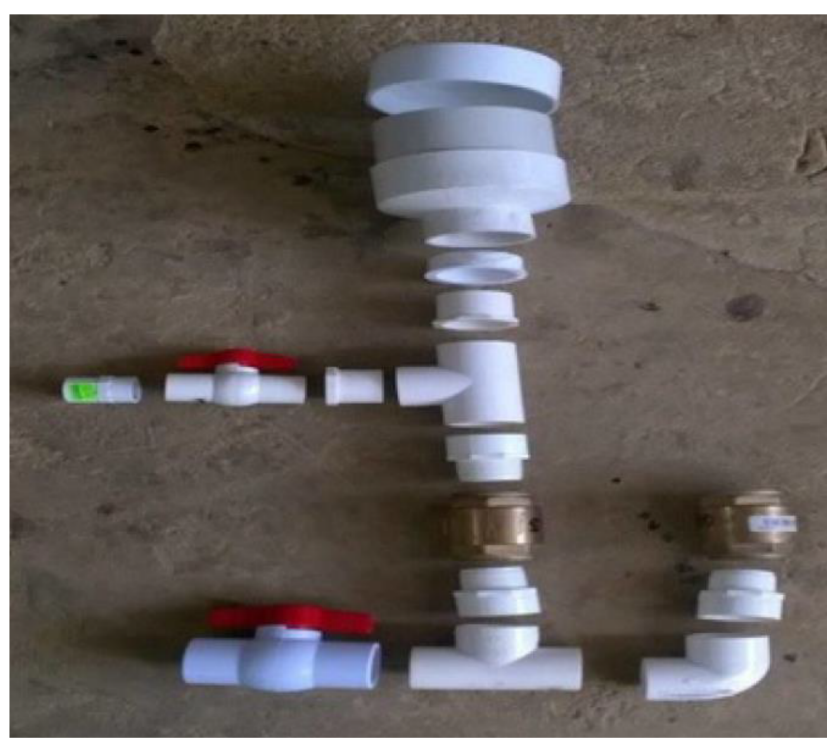

Figure 2. Photograph of the pump components.

end attached to the $32 \mathrm{~mm}$ pipe. Figure 2 is a photograph of the pump components in the assembly position. The materials/components required for the pump construction were obtained from the local hardware store. The cost of the components for the pump construction are shown in Table 1. The total cost of the pump components was TTD 178, which is equivalent to USD 26.

Figure 3 shows a schematic of the experimental apparatus. The experimental set-up for testing the water-hammer head pump was designed with a variable head input (a) and an adjustable head output (b). The water supply was from a $5000 \mathrm{~L}$ water reservoir (c). The constant head supply tank was designed with a float (d) that maintained the constant water level as water was supplied to the inlet of the pump. The input head was the difference in height between the in-

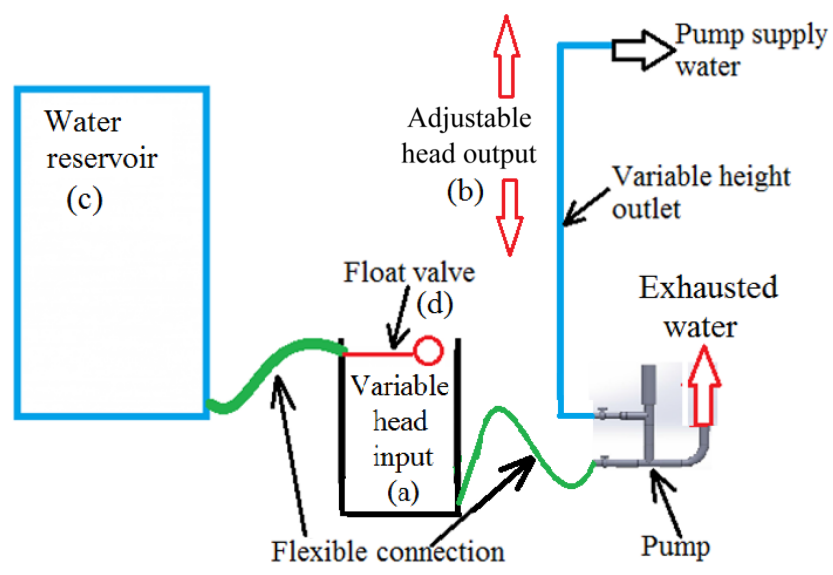

Figure 3. Schematic of the experimental set-up.

let of the pump and the water level at the top of the constant head supply tank. The outlet side of the pump used a variable length of $13 \mathrm{~mm}$ diameter PVC pipe to adjust the delivery height (b).

The water supplied by the pump was collected at fixed time intervals during operation, and the volume was measured with a $2000 \mathrm{~mL}$ measuring cylinder with an accuracy of $\pm 20 \mathrm{~mL}$ to determine the pump supply flow rate. The exhausted water from the pump was also collected at fixed time intervals during operation, and the volume was measured with a $2000 \mathrm{~mL}$ measuring cylinder with an accuracy of $\pm 20 \mathrm{~mL}$ to determine the pump exhausted water flow rate.

\section{Results and discussion}

Experiments were conducted by varying the input head of the water at between 30 and $150 \mathrm{~cm}$ in increments of $30 \mathrm{~cm}$. At each corresponding input head the pump outlet height was varied between 60 and $600 \mathrm{~cm}$ in increments of $60 \mathrm{~cm}$. For each test configuration, a total of 10 samples of pump supply water and pump exhausted water were collected. The water samples were collected for $30 \mathrm{~s}$ in each case. The volume of water for each sample was measured, and the average volume flow rate for the 10 samples was calculated. This procedure was repeated for each combination of supply head and pump outlet height. The calculated results were tabulated and are shown in Tables 2 and 3.

The simple construction low-cost water-hammer pump showed that as the delivery head increased, the rate of water delivered decreased for the five input head heights tested. For the lowest input head height of $30 \mathrm{~cm}$, the pump operated up to a maximum height of $300 \mathrm{~cm}$. No water was delivered beyond this height. For input head height of $60 \mathrm{~cm}$, the pump operated up to a maximum height of $480 \mathrm{~cm}$. No water was delivered beyond this height. For input head heights of 90, 120 and $150 \mathrm{~cm}$, the pump delivered water up to the maximum test height of $600 \mathrm{~cm}$. A plot of the data points indicated 
Table 1. Cost of the pump components.

\begin{tabular}{lr}
\hline Component & TTD (Trinidad and Tobago dollars) \\
\hline Two one-way swing valves (brass) & 70 \\
One 25.4 mm PVC ball valve & 15 \\
A $50 \mathrm{~cm}$ length of PVC pipe (32 mm diameter) & 5 \\
One 13 mm PVC ball valve & 10 \\
A 50 cm length of PVC pipe (75 mm diameter) & 10 \\
Two PVC end caps (75 mm diameter) & 12 \\
One PVC reducer 75 to $32 \mathrm{~mm}$ & 8 \\
One PVC reducer 25.4 to $13 \mathrm{~mm}$ & 3 \\
Three male adapters $32 \mathrm{~mm}$ & 9 \\
One PVC elbow $32 \mathrm{~mm}$ & 4 \\
Two PVC “T” 25.4 mm/32 mm & 20 \\
One PVC male adapter $13 \mathrm{~mm}$ & 2 \\
PVC glue (50 mL) & 10 \\
\hline
\end{tabular}

Table 2. The pump output water flow rate variation with input head and outlet height.

\begin{tabular}{lrrrrrrrrrr}
\hline & \multicolumn{10}{c}{ Pump outlet height (cm) } \\
\cline { 2 - 11 } & 60 & 120 & 180 & 240 & 300 & 360 & 420 & 480 & 540 & 600 \\
\hline Input head (cm) & \multicolumn{10}{c}{ Water flow rate at pump outlet (pump supply water) $\left(\mathrm{mL} \mathrm{min}^{-1}\right)$} \\
\hline 30 & 3600 & 2700 & 1200 & 700 & 100 & 0 & 0 & 0 & 0 & 0 \\
60 & 5600 & 4800 & 3800 & 2700 & 1600 & 1000 & 400 & 200 & 0 & 0 \\
90 & 7000 & 6800 & 6000 & 4800 & 4200 & 3100 & 2000 & 1500 & 700 & 400 \\
120 & 8000 & 7800 & 6600 & 5200 & 4400 & 4000 & 3280 & 2400 & 1900 & 1800 \\
150 & 8800 & 8400 & 8200 & 5600 & 4800 & 4400 & 4000 & 3000 & 2400 & 2200 \\
\hline
\end{tabular}

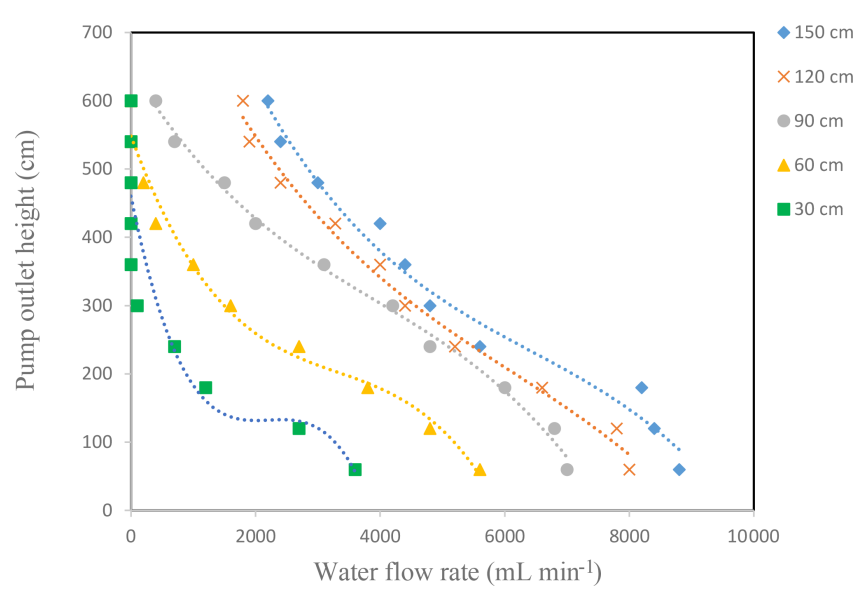

Figure 4. Graph of supply water flow rate vs. pump outlet height for various input head heights.

a non-linear relationship between the pump outlet height and the delivered water flow rate, as shown in Fig. 4. This observation is in agreement with published literature (Taye, 1998; Tijsselingc and Berganta, 2012; Fatahi-Alkouhi et al., 2015).

The experimental data showed that as the pump outlet height decreased, there was a slow increase in the delivered water flow rate. This was followed by an increase in the delivered water flow rate with an almost linear variation. This observation is in agreement with published literature (U.S. Department of Agriculture Natural Resources Conservation Service, 2007; Tijsselingc and Berganta, 2012). When the pump outlet height dropped below $120 \mathrm{~cm}$, there was a decrease in the delivered water flow rate. The pump efficiency was determined from the ratio of the water delivered to the total water flow. The values were calculated and are tabulated in Table 4.

From the data for the 60 and $30 \mathrm{~cm}$ input head heights, the pump was capable of delivering water be between 8 and 10 times the input head height with efficiencies of $1.6 \%$ and $0.9 \%$, respectively. This was within the range of 5 to 25 times as published by U.S. Department of Agriculture Natural Resources Conservation Service (U.S. Department of Agriculture Natural Resources Conservation Service, 2007). The difference in the delivery height capacity may be due to the shorter $300 \mathrm{~cm}$ pipe length compared with the $480 \mathrm{~cm}$ length associated with the 30 and $60 \mathrm{~cm}$ input head heights, respectively. For the increased pipe length there would be increased frictional resistance to flow and increased gravitational force due to the higher water column. For input head heights ranging between 30 and $150 \mathrm{~cm}$, the efficiency of the pump deliv- 
Table 3. The pump exhausted water flow rate variation with input head and outlet height.

\begin{tabular}{lrrrrrrrrrr}
\hline & \multicolumn{10}{c}{ Pump outlet height $(\mathrm{cm})$} \\
\cline { 2 - 11 } & 60 & 120 & 180 & 240 & 300 & 360 & 420 & 480 & 540 & 600 \\
\hline Input head $(\mathrm{cm})$ & \multicolumn{10}{c}{ Water flow rate at pump exhaust (pump waste water) $\left(\mathrm{mL} \mathrm{min}^{-1}\right)$} \\
\hline 30 & 11600 & 11200 & 16400 & 10600 & 10500 & 0 & 0 & 0 & 0 & 0 \\
60 & 12800 & 12800 & 15000 & 12600 & 12600 & 12600 & 12400 & 12400 & 12400 & 12400 \\
90 & 13800 & 13800 & 13600 & 13600 & 13600 & 13400 & 13400 & 13200 & 13200 & 13200 \\
120 & 14800 & 15200 & 12800 & 15000 & 14800 & 14800 & 14400 & 14400 & 14400 & 14400 \\
150 & 16000 & 16000 & 11000 & 16400 & 16000 & 15600 & 15200 & 15000 & 14800 & 14400 \\
\hline
\end{tabular}

Table 4. The pump efficiency variation with input head and outlet height.

\begin{tabular}{lrrrrrrrrrr}
\hline & \multicolumn{10}{c}{ Pump outlet height (cm) } \\
\cline { 2 - 11 } & 60 & 120 & 180 & 240 & 300 & 360 & 420 & 480 & 540 & 600 \\
\hline Input head (cm) & & \multicolumn{10}{c}{ Pump efficiency (\%) } \\
\hline 30 & 23.7 & 19.4 & 6.8 & 6.2 & 0.9 & 0 & 0 & 0 & 0 & 0 \\
60 & 30.4 & 27.3 & 20.2 & 17.6 & 11.3 & 7.4 & 13.0 & 1.6 & 0 & 0 \\
90 & 33.7 & 33.0 & 30.6 & 26.1 & 23.6 & 18.8 & 13.0 & 10.2 & 5.0 & 2.9 \\
120 & 35.1 & 33.9 & 34.0 & 25.7 & 22.9 & 21.3 & 18.6 & 14.3 & 11.7 & 11.1 \\
150 & 35.5 & 34.4 & 42.7 & 25.5 & 23.1 & 22.0 & 20.8 & 16.7 & 14.0 & 13.3 \\
\hline
\end{tabular}

ering water at twice the input head height ranged from $23.1 \%$ to $30.6 \%$ with an average efficiency of $26 \%$. For input head heights ranging between 30 and $150 \mathrm{~cm}$, the efficiency of the pump delivering water at 4 times the input head height ranged from $19.4 \%$ to $13.3 \%$ with an average efficiency of $16.6 \%$. From the three sets of data available for input head heights ranging between 30 and $90 \mathrm{~cm}$, the efficiency of the pump delivering water at 6 times the input head height ranged from $5.0 \%$ to $7.4 \%$ with an average efficiency of $6.4 \%$. This trend indicated that as the delivery height increased in increments of 2 times the corresponding input head, there was a $10 \%$ decrease in efficiency. This observation is in conformity with the operation of the hydraulic ram pumps (Fatahi-Alkouhi et al., 2015).

\section{Conclusions}

The main conclusions of this study are as follows:

- The delivered water flow rate showed a non-linear variation with respect to the pump outlet height.

- The pump was capable of delivering water to a maximum height of 8 to 10 times the height of the input head.

- The pump operated at average efficiencies of $26 \%$, $16 \%$ and $6 \%$ when the delivery height was 2,4 and 6 times the input head height, respectively.
- There was a 5\% incremental decrease in pump efficiency as the delivery height increased in increments of the corresponding input head height.

Data availability. The underlying research data are part of a final year bachelor of science mechanical engineering project report. The project report is entitled "Design, build and test of a low cost hammer-head pump" by Kureem Vialva, 2017. The project report can be requested from the final year project depository at the Mechanical and Manufacturing Engineering Department, The University of the West Indies, St. Augustine Campus, Trinidad and Tobago, West Indies.

Author contributions. KM compiled the original paper and was responsible for addressing all reviewers' comments and correspondence. AAA reviewed the original paper, made editorial corrections and prepared the figures and tables. KV conducted the experiments and recorded the original data.

Competing interests. The authors declare that they have no conflict of interest.

Acknowledgements. The authors would like to acknowledge the Department of Mechanical and Manufacturing Engineering, The University of the West Indies, for providing the facilities for conducting this research. 
Review statement. This paper was edited by Luuk Rietveld and reviewed by Maurits Ertsen and one anonymous referee.

\section{References}

Asvapoositkul, W., Juruta, J., Tabtimhin, N., and Limpongsa, Y.: Determination of Hydraulic Ram Pump Performance: Experimental Results, Adv. Civil Eng., 2019, 9702183, https://doi.org/10.1155/2019/9702183, 2019.

Berganta, A., Simpsonb, A. R., and Tijsselingc, A. S.: Water hammer with column separation: A historical review, J. Fluids Struct., 22, 135-171, 2006.

De Montgolfier, J. M.: Note sur le bélier hydraulique, et sur la manière d'en calculer les effets (Note on the hydraulic ram, and on the method of calculating its effects), Journal des Mines, 13, 42-51, 1803.

Dzvurumi, F.: Evaluation of Emergency Small Scale Irrigation Projects in Southern Africa, Emergency Operations and Rehabilitation Division (TCE), Final Report, July, 2006.

Engel, B. A. and Ahiablame, L.: Design of a Low Cost, SelfOperating Hydraulic Ram Pump for Water Retention and Lifting in Developing Countries, Bringing Clean Water to Haiti, United States Environmental Protection Agency, Purdue University, Project Period: August 15, 2011 through August 14, 2012.

Fatahi-Alkouhi, R., Lashkar-Ara, B., and Keramat, A.: Determine the Efficiency of Hydraulic Ram-Pumps, E-Proceedings of the 36th IAHR World Congress, The Hague, the Netherlands, 28 June-3 July, 2015.

Food Security Support Programme (TCSF), Review of water control technologies in the FAO programmes for food security, Rome, available at: http://www.fao.org/3/i2176e/i2176e00.pdf (last access: 23 August 2019), 2011.

Garg, H. P.: Solar Powered Water Pump, in: Advances in Solar Energy Technology, Springer, Dordrecht, https://doi.org/10.1007/978-94-009-3797-0_4, 1987.

Lansford, W. M. and Dugan, W. G.: An analytical and experimental study of the hydraulic ram, University of Illinois Bulletin, 38, 1-70, 1941.
Mohammed, S. N.: Design and Construction of a Hydraulic Ram Pump, Leonardo Electronic Journal of Practices and Technologies, 11, 59-70, 2007.

Papa Hydraulic Ram Pump, Water Powered, Fuelless, Gravity, Eco Pump Kit -2 inch including Seradisc Filters, available at: https://www.amazon.com/Papa-Pump-Hydraulic-Water-system/ dp/B06XXTMF4Q (last access: 23 August 2019), 2019.

Ningbo Marshine Power Technology Company: 24 hours uninterrupted lift water machine automatic hydraulic ram pump, available at: https://www.alibaba.com/product-detail/ 24-hours-uninterrupted-lift-water-machine_60572542323. html?spm=a2700.7724857. normalList.2.20173dbdfO4fjp （last access: 23 August 2019), 2019.

Taye, T.: Hydraulic ram pump, J. ESME, 2, available at: https: //medium.com/atf-articles/hydraulic-ram-pump-8d097413c446 (last access: 23 August 2019), 1998.

Tijsselingc, A. S. and Berganta, A.: Exact computation of water hammer in a three reservoir system, Eindhoven University of Technology, CASA-Report 12-41:1-10, 2012.

U.S. Department of Agriculture Natural Resources Conservation Service: Technical Notes: Portland, Oregon, Technical note No. 26; Hydraulic Ram Pumps, available at: https://www.nrcs.usda. gov/Internet/FSE_DOCUMENTS/nrcs142p2_041913.pdf (last access: 23 August 2019), 2007.

Water Service (NRLW), Irrigation Manuals for Agricultural Engineers, 1 to 14, Rome, Land and Water Media CD-Rom No 37, available at: http://www.fao.org/nr/water/docs/FAO_ LandandWater_37.zip (last access: 23 August 2019), 2004.

Whitehurst, J.: Account of a Machine for Raising Water, Executed at Oulton, in Cheshire, in 1772, Phil. Transact., 65, 277-279, https://doi.org/10.1098/rstl.1775.0026, 1775.

Yao, E., Kember, G. C., and Hansen, D.: Analysis of Water Hammer Attenuation in Applications with Varying Valve Closure Times, J. Eng. Mech., 141, 04014107 , https://doi.org/10.1061/(ASCE)EM.1943-7889.0000825, 2015.

Young, B. W.: Simplified analysis and design of the hydraulic ram pump, in: Proceedings of the Institution of Mechanical Engineers, Part A: Journal of Power and Energy, 210, 295-303, 2016. 